\title{
Health Identity: Theoretical and empirical development of a health education concept
}

\author{
Dr. Dan Grabowski \\ Health Promotion Research \\ Steno Diabetes Center, Denmark \\ Email:dgbo@steno.dk
}

Doi:10.5296/ jsr.v6i1.7754 URL: http://dx.doi.org/10.5296/ jsr.v6i1.7754

\begin{abstract}
In school-based health education, it is often difficult to present health in ways children and adolescents accept as relevant and meaningful. This often results in misconceived approaches that have little or no effect on acquisition of health knowledge or changes in health behaviour. Many approaches only manage to appeal to children and adolescents who are already healthy. One way to approach this is to look at the role identity plays in health. Implementing a concept of identity within health education poses two main challenges, which are addressed in the objectives of the present paper: to theoretically and empirically develop a concept of health identity, and to make this concept useable in health education practice. Against the backdrop of these challenges and objectives, the paper proposes the following definition of a concept of health identity: "Children's and adolescents' observations and expectations concerning their own health, their knowledge about health and in what ways their health is related and comparable to the health of others." This health identity concept - based on Luhmann's theories of observation and expectational structures supplemented with Taylor's theories on social imaginaries and horizons of significance - provides a new framework for identity theory and health education research and development.
\end{abstract}

Keywords: Identity, Health, Theory, Education, Observation 


\section{Introduction and background}

In school-based approaches to health education, it is often difficult to present health messages in ways children and adolescents accept as relevant, authentic and meaningful (Grabowski, 2013a; Grabowski \& Rasmussen, 2014a; Wistoft, 2010). This often results in misconceived campaigns and approaches that have little or no effect on acquisition of health knowledge or changes in health behaviour. More often than not, such campaigns and approaches only manage to appeal to children and adolescents who are already healthy, and therefore there is a risk that they will serve to increase the difference between those who are healthy and those who are not (Peters et al., 2009; Grabowski, 2013b; Grabowski \& Rasmussen, 2014b).

Much of the literature on how to approach health education in school deals with the basic challenges concerning how to present health knowledge so that pupils will want to make use of this knowledge. Prelip et al. evaluate a school-based multicomponent nutrition education programme intended to increase young children's fruit and vegetable consumption (Prelip et al., 2012). Although this study shows that the programme did influence knowledge and attitudes, no significant increase in pupils' fruit and vegetable consumption could be observed. This represents a classic and persistent challenge within health education: How can we proceed from knowledge to concrete action, and what concept or procedural element constitutes the missing link? The present paper suggests that health identity may be a contender for the role of this missing link - both in practice and in theory.

Petraglia discusses the importance of being authentic as well as how to create learning environments that provide learners with richer and more realistic contexts in which to apply knowledge and practice skills - in other words, how to translate knowledge into action in specific settings. Many health messages presented to children and adolescents are not so much imprecise or incomprehensible as they are simply inauthentic and unrelatable to self-understanding and identity (Petraglia, 2009).

Another important issue is the classic health education challenge of inequality in health. Mohajer and Earnest state that there is a gap in our knowledge about what strategies are needed to address elements of inequality from a health education perspective (Mohajer \& Earnest, 2010). Given that health identity is naturally related to differences in perceptions of being either healthy or unhealthy, Grace et al. take this identity relevance a step further by studying teenagers' views on their own health and the health of their future children (Grace et al., 2012). In doing so, they relate the discussion to theories about narrative identity and perceptions of future selves. When considering and interpreting these matters, it is of central importance to look at aspects of the past, present and future, and at how these play a role in the way we understand ourselves in the context of our own health and health in general.

One possible way to approach these challenges is to look at the role identity plays in health, in general, and in health education, in particular. Identity is rarely used as an active concept within health education. Implementing a concept of identity within health education poses two main challenges, which are addressed in the objectives of the present paper: to theoretically and empirically develop a concept of health identity, and to apply this theoretical innovation to health education practice. Against the backdrop of these challenges and 
objectives and based on empirical studies (Grabowski 2013a \& 2013b; Grabowski \& Rasmussen, 2014a \& 2014b), the paper develops and uses the following definition of health identity: "Children's and adolescents' observations and expectations concerning their own health, their knowledge about health and in what ways their health is related and comparable to the health of others."

Implementing an identity concept in health education research does however present several challenges. Bendle describes how the increased focus on identity renders use of the concept "inconsistent, under-theorized and incapable of bearing the analytical load required" (Bendle, 2002: 1). Hall similarly focuses on a paradoxical development in recent years, where both a discursive explosion in use of the concept of identity and growing criticism of it have resulted in a kind of conceptual deconstruction. Hall indicates that many identity-concepts are no longer useable or good for thinking with in their original and unreconstructed form, and that because there are no new conceptual innovations, there is nothing to do but continue to think with them (Hall, 2001).

There are only a few examples of research in which health is seen as a domain for identity development. Attempts at relating health to identity are often restricted to research on experiences with serious illness. This makes sense, as chronic illness represents an identifiable disruption of normality that can be explained relatively straightforwardly using theory on identity crisis (e.g., Karnilowicz, 2011; Vickers, 2012). Another example of this tendency is found in the psychiatric research on illness identity - often defined as the set of roles and attitudes a person develops in relation to having a mental illness (e.g., Yanos et al., 2010). When it comes to health education, identity would seem to be an undervalued concept, as there are no examples of researchers employing a concept of identity as the central part of a health education research project.

\section{Theoretical approach}

Constructing and defining a concept of health identity entails a double challenge. Not only do we need to describe the relevance of linking identity and health education; we also have to theoretically define a new and useable concept of identity. This concept should be both complexity-oriented and practically applicable in a way that corresponds with how children and adolescents experience themselves and each other.

The main component from Luhmann's systems theory used in the present theoretical construct is the concept of observation. All innovations, ideas, developments and analytical advances hail more or less directly from this concept. What is intriguing and complicated in Luhmann's theory, however, is the fact that none of the multitude of concepts really makes much sense without a minimum of understanding of the theory as a whole. Therefore, to fully grasp the theoretical scope of the concept of observation, it is necessary to explain some of the other concepts within the systems theory.

Applying Luhmann's systems theory to a health identity concept is complicated by the fact that Luhmann did not develop or in any elaborate way describe an identity concept as part of his theory. This rejection on Luhmann's part can be seen as an example of theorists not 
wanting to work with a concept of identity, because the theoretical overexposure of and general confusion over the concept makes it difficult. In Luhmann's case, it is very likely that his dismissal of the concept may be explained by the fact that his theory primarily focuses on social rather than psychological systems.

This distinction between psychological and social systems is a good entry point to the systems theory. What Luhmann calls psychological systems is in fact what others might call persons, individuals or subjects, and for Luhmann social systems can be interactions, organizations or societies. He describes how psychological systems operate on the basis of consciousness and social systems on the basis of communication - which means, that a social system cannot think and a psychological system cannot communicate (Luhmann, 2002). In other words, the consciousness of the psychological systems and the communication of the social systems do not have direct access to each other. They basically speak different languages, and this means that the psychological systems (individuals or subjects) are restricted to observing the communicative social systems. The systems are closed and autopoietic, which means that each system continually self-interprets and self-reflects on the basis of its contents.

The notion that people cannot communicate, and that only communication can communicate, sounds abstract to most ears. Nonetheless, this is one of the key points in understanding why systems theory is relevant to a concept of health identity and to how children and adolescents understand each other and acquire knowledge. This inability to fully understand the other kind of system is basically Luhmann's way of addressing the classical sociological issue of the co-evolution of the social and the individual. In Luhmann's case, a key fixture is each system's unique environment, which in turn makes every system equally unique. Every system removes only itself from its environment - making the environment of each system different from any other systems' environment (Luhmann, 1995). Every child and adolescent (or at least the psychological system constituted by his or her consciousness) has a unique environment that is different from all other children's and adolescents' environments. This also makes the child or adolescent different from any other child or adolescent. Every child observing his or her environment is observing something slightly different than what every other child is observing. This is important to bear in mind in health education, as every child will observe the health messages in a slightly different way than his or her classmates will and the messages will therefore mean something different in the context of the different environments.

That the systems are closed means that the consciousness that continually recreates the way we (as psychological systems) interpret and understand ourselves in the context of our own unique environment always comes from within the system itself. Consciousness never comes from the outside, as we never get consciousness from other psychological systems or from social systems. We are therefore closed in terms of this operational element. It is this self-reference that makes it possible for systems to continually distinguish themselves from their environment. The concept of self-reference is therefore essential in understanding how the individual system is able to maintain its own horizon of meaning despite the complexity pressure of the environment (Luhmann, 1990). In other words, the psychological system 
continues to produce the consciousness needed to maintain a sense of meaning, while at the same time observing and trying to understand the environment. At this point, we have arrived at a paradox: While the systems are closed in terms of their self-reference, they are in fact at the same time open as regards observing the environment. The concept of observation is therefore essential to how systems evolve and change.

To actively try to understand and make sense of the environment, the child or adolescent needs to continually recreate his or her own self-understanding and sense of meaning. It is on the basis of the self-understanding and sense of meaning that the actual observations are made. This concept of meaning is therefore of essential importance to systems theory, especially regarding the co-evolution of psychological and social systems. (Luhmann, 1995)

All of this comes down to systems observing systems and trying to make sense of it all. The basic operation, when observing, is making a distinction. When a person (or rather his or her psychological system) indicates and observes something, he or she is automatically not observing something else. Or, rather, he or she is not observing the rest of the environment. When children or adolescents are observing anything health related in any given setting, they are automatically not observing something else in relation to the health-related issue and/or the setting. By analysing how, where and why these observations are made, it is possible to analytically sharpen our focus on why children and adolescents do not observe what they do not observe. Why does a certain way of observing and understanding health or each other as either healthy or unhealthy supply meaning to some observing systems and not to other observing systems?

To further elaborate on the concept of observation, it is necessary to move on from the concept of observations to what Luhmann calls expectational structures, or simply expectations. These expectational structures are a way of navigating in the complex environment of possible observations. By ascribing expected meaning to different contexts or relations, a person will have an idea about where it is most likely he or she will be able to observe meaning in relation to him- or herself or in relation to any given prior observation (Luhmann 1995). These expectations are bundled together and provide expectations with identificational perspectives that make it possible to know where to observe meaningfully.

Using the concepts of observation and expectational structures when analysing contemporary school contexts entails a focus on how these structures are complex and on how the teachers, curriculum and environment play central roles in how identities are more or less observable in the individual school.

In contrast to Luhmann, Taylor does indeed use a concept of identity quite prominently in his theories. In his description of what he calls horizons of significance, he links identity to knowledge and meaning. He states: "I can define my identity only against the background of things that matter." (Taylor, 1991: 40) This quote can be used to describe why some children and adolescents are able to define their identity against the background of issues related to health, and why some cannot relate to these issues at all. What matters to some does not matter to others, and what is deemed meaningful in some school classes is irrelevant in others. Taylor talks about these things that matter in the context of authenticity in contemporary 
cultures and societies, thus very much describing the interplay between the individual and the social - between psychological and social systems.

Taylor goes on to talk about what it takes for people to be able to define themselves and distinguish themselves from other people. It is not enough to simply be different from others. One needs to be different in areas that matter and make sense to other people. If health matters within a certain social context, then being different within that particular horizon of meaning will have significance, because it will be within the domains of recognizable self-definitions (Taylor, 1991). In relation to identity formation, the domains of recognizable and therefore possible self-definitions are important, as these limit the scope of acceptable and meaningful identities for both the individual person and the social context. In a classroom or in a school, these recognizable self-definitions will at all times determine which health-related issues are important enough to form the basis of self-definitions - and therefore also which issues are important enough to be different from others within.

As such, horizons of significance are also directly connected to individual choice, in the sense that choices in reality are restricted to fit within the horizons. If self-choice is not really self-choice, then the choice to act positively on the basis of health knowledge and health information is not in reality an open choice either. In a health education context, where health choices and health behaviour are of central concern, the connection between identity, choice and behaviour is essential when exploring the missing link between knowledge and action.

The concept of social imaginaries adds a relational aspect to the case of acquiring and acting on the basis of identity. It also elaborates on the connections between expectations and common understandings of how we choose and act in society and in relational contexts: "...the ways people imagine their social existence, how they fit together with others, how things go on between them and their fellows, the expectations that are normally met, and the deeper normative images that underlie these expectations." (Taylor 2004: 23). This can be used to clarify how difficult it is to make changes in health behaviour - on an individual level as well as on group or societal level. There will always be an element of having to fit in with a certain group and an ensuing element of imagining how that group might interpret these changes. On the other hand, it is equally difficult to choose not to change, if a certain change becomes the norm and thereby the expected behaviour.

What we end up with theoretically when combining Luhmann and Taylor is a concept of health identity based on observations within horizons of significance: persons (psychological systems) observing identities (their own and others') in the communicatively constituted social contexts - and social systems observing identities in their ever-changing environments. Health identity is observations based on meaning and on the expectational structures and social imaginaries of both the observed and the observing system. The concept of health identity entails a focus on how the psychological systems try to affect the meaning within the social systems by trying to communicate and thereby actively affect the construction of their own (and others') identities.

In everyday language, we get a concept with which we can describe and analyse how children and adolescents define themselves and each other as healthy or unhealthy, how they relate to 
health education and acquire health knowledge based on these definitions, and whether and how they act according to this knowledge.

The distinction between Luhmann's expectational structures and Taylor's social imaginaries provides two access points for looking at how adolescents ascribe current and future meaning to their health. Expectational structures describe structures that determine where the adolescents direct their observations and, perhaps most importantly, what they do not observe. Social imaginaries describe how the adolescents compare themselves to others, how they expect to fit in and how they imagine other people's imaginaries.

It is in relation to social imaginaries that Luhmann and Taylor truly complement each other well. The most important part of the concept of social imaginaries is the fact that the child or adolescent is trying to imagine how his schoolmates think he or she fits in. This is exactly the point of Luhmann's theories of systems that do not fully understand each other. The child or adolescent is trying to understand some of the communicatively constructed meaning in the social systems of the school or the classroom. Unable to accomplish this in full, he or she has to rely on imaginings that are based on his or her own self-reflecting consciousness. In this light, health identity is a concept that manages to focus on the observations between systems rather than on the exact contents of these systems. By doing this, the concept avoids the pitfall of being focused on either describing identity as a core or as a patchwork.

Adding horizons of significance to the theory of observations gives the analysis an extra element of sensitivity to the social construction of meaning and to how these constructions actually affect patterns of observation, thereby determining what is observed as meaningful for identity development and what is not.

This entire theoretical construct is somewhat unusual in the context of traditional identity research. It is therefore helpful to take a look at a couple of the more established identity theories if we are to understand how the theoretical construction of health identity fits in among these other theories. Waterman defines identity as: "a clearly delineated self-definition comprised of the goals, values, and beliefs to which the person is unequivocally committed. These commitments evolve over time and are made because the chosen goals, values, and beliefs are judged worthy of giving a direction, purpose, and meaning to life" (Waterman, 1984: 331) Nothing in this definition lies outside the concept of health identity. Waterman focuses on how goals, values and beliefs give direction, purpose and meaning. This is another way of pointing out that observations made on the basis of a person's self-reference are part of a perpetual process of making sense and ascribing meaning to the observed environment and especially on how to fit into that environment. Every observation changes the background against which the next observation is made, causing what Waterman labels evolving commitments. Whereas Waterman speaks about individual choice, an identity concept based on Luhmann and Taylor would argue that self-choice is not actually a choice but rather a process of observing the contextual construction of what choices are acceptable and significant enough to meaningfully observe oneself within.

Marcia (based on Erikson's theories) gives us this short definition: "Identity refers to a sense of oneself as having continuity with the past, active direction in the present, and a future 
trajectory" (2014:168). This definition fits very nicely with the identity concept constructed in the present paper. What Marcia describes are simultaneous observations (and thereby constructions of meaning) of the past, present and future. This is a good example of how the construction of a new identity concept is not at odds with the classic definitions at all. It just adds an element of complexity orientation and a theoretical and methodological grip to understand (and work with) the observational element that constitutes identities.

In the presentation of empirical examples I will use this definition of health identity: "Children's and adolescents' observations and expectations concerning their own health, their knowledge about health and in what ways their health is related and comparable to the health of others. " Health identity is developed on the basis of individual observations (and consequent meaning making) of communication and is expressed through expectational structures and social imaginaries with an impact on health values, health beliefs and health choices. Health identity functions as a way of orientation and navigation in the complexities of health education, health information and possible health behaviours.

\section{Empirical examples}

The data presented to exemplify and contextualize the health identity concept stem from recently published studies of three Danish health education initiatives: Study 1: a health theatre for young children (Grabowski, 2013a), Study 2: a health computer game for adolescents (Grabowski, 2013b) and Study 3: health courses for adolescents (Grabowski \& Rasmussen, 2014a \& 2014b). The empirical and analytical methods used in the three studies are similar. All studies use group interviews with children/adolescents and individual interviews with teachers, and make use of radical hermeneutics as their analytical framework. For full methodological descriptions and research results, please see the individual papers reporting on the respective studies.

Here, the data from the three studies are compared, re-interpreted and re-presented in five themes of relevance to different aspects of the health identity concept, the theoretical elements and health education practice. As the combined data are comprehensive, the presented examples represent only a small portion of the entire dataset.

\section{Expectations and imaginaries}

All three studies indicate that the way children and adolescents understand themselves and their peers as either healthy or unhealthy is determined by a multitude of expectations and imaginaries that direct how, where and when they observe and make sense of health identities. The young boy below is answering a question about why he is not particularly interested in anything related to health: "I'm probably more like an indoor kind of guy. But sometimes I go outside a bit and play with friends from my class, but that's not really my favourite thing. I really like to be indoors. I don't do healthy stuff. Me and Magnus we're kind of unhealthy, I think. We don't play as much football as the rest of the guys. But that's just who we are." (Boy, second grade - Study 1) Throughout the interview, this boy made it very clear that everything remotely associated with health was unimportant and irrelevant to him. A significant part of his identity revolved around one solid fact: he was not healthy at all. He simply expects 
himself to be unhealthy and accordingly observes himself meaningfully in unhealthy settings. All of the classmates in the group interview agreed with this, and they also found it natural that he, as an unhealthy boy, would not be interested in activities and information concerning health. These interconnected observations mean that the boy finds it difficult and unimportant to relate to the presented health information in the theatre and they furthermore make it necessary for him, if he is to observe his own identity at all, to observe and validate himself as the unhealthy boy.

The next quote tells us something about how young people construct very clear-cut and well-defined expectations and imaginaries and thereby perpetually confirm each other's health identities: "The people from our class who don't live a healthy life, they only sat there quietly. I don't really know if they got anything out of it. They didn't really say anything, so we don't know if they paid attention or learned anything. We have one guy, who just sleeps most of the time." (Girl, seventh grade - Study 2) This girl has very clear expectations and imaginaries about the unhealthy children, in general, and about the sleeping guy, in particular. In a health education context, this is important and tells us something about why children and adolescents, who are seen as unhealthy and therefore see themselves as unhealthy, do not participate in health education activities and do not acquire any health knowledge. They basically do not ascribe any value or meaning to things associated with health, because it has no place in their daily lives and therefore no place in their future either.

That the process of developing, maintaining and changing health identities can be seen as psychological and communicative systems observing each other and thereby creating and re-creating expectations and imaginaries is especially apparent when children, adolescents and their teachers discuss and evaluate each other's performance at the various health education activities: "Some of our classmates don't do any sports at all. They had a really hard time at the course. They're the ones who just sit at home and play computer games and eat crisps all day long. It was hard for them." (Boy, seventh grade - Study 3). "You had all the computer boys and it was almost scary to see, all the things they just couldn't do. I think they really surprised themselves. They didn't expect to do so badly. I knew that all the girls would be good at it. They're very active girls." (Teacher, seventh grade - Study 3). Both the boy and the teacher are discussing the class' participation in a rather physically demanding health course which makes the differences between healthy and unhealthy very obvious. The quotes illustrate how the school class (as a social system) creates easily observable health identities that form the expectations and imaginaries that teachers and pupils observe each other on the basis of.

Using a health identity concept to understand these mechanisms gives us insight into the interconnected observations that determine the structures of future observations, thereby making it difficult for children and adolescents to change these identities actively. These communicatively constructed and continually confirmed identities are, however, flexible and thus possible to affect and change. Teachers have a potential role in this. 


\section{The teacher's role in the development of health identities}

Teachers' observations of their pupils continually affect how the pupils observe themselves and how they observe themselves being observed. This is a good example of how the imaginaries and expectations of some individuals affect the imaginaries and expectations of others. "I think that the weak and insecure adolescents will fall through no matter what I do. Those who are in between might be possible to save. Those who are already firm in their healthiness will only be confirmed in their healthy behaviour and will keep doing the right thing because now they know that they'll live to be 110 years old" (Teacher, $7^{\text {th }}$ grade - Study 2) This teacher has a clear image of who is and who is not healthy among the pupils in the class. That image comes with very explicit expectations as to whether or not individual pupils have the potential to learn anything from the health education initiative. These expectations will no doubt affect how the health education is conducted in the class and how the pupils observe each other as healthy or unhealthy. The adolescents in the teacher-constructed "weak-pupil category" are not likely to acquire any health knowledge or competences, as nobody (least of all themselves) expects anything of the sort from them. They are generally observed as unhealthy and therefore uninterested in health. Nobody in their immediate environment has any expectations that these adolescents will be able to change their health behaviour, and this lack of expectations is clearly observable among the adolescents themselves. This teacher-constructed health hierarchy is an explicit example of how teachers' observations (as well as those of other significant people in children's and adolescents' immediate environment) strongly affect the development of health identities.

The teacher quote above is not an isolated case. Another teacher from the same study divides his pupils into two groups and then arrives at the rather depressing conclusion that neither group is expected to gain anything from the health education initiative: "The strong kids from homes where these things are reflected on regularly, they don't bring any of this home. It only confirms the things they already do at home. The few kids in my class who come from families, where they don't live a healthy life, they won't bring much home either." (Teacher, $9^{\text {th }}$ grade study 2) The teacher observes the adolescents' home environments as an indicator of whether or not they will benefit from the health education, and in doing so he also attempts to observe their self-observations. The pupils, in turn, observe him observing and categorizing all the adolescents in the class. The expectations that accompany these categorizations are related to both present and future health status. The teacher furthermore believes that these health identities are so well-established that he cannot affect them.

In the study of the young children's participation in health theatre neither teachers nor supervisors had the resources or interest to try to incorporate the theatre into the daily routines or to use the curiosity generated by the performances to engage children in discussions about health and everyday life: "We haven't had the time or the resources to prepare the children for the play or to talk to them about it afterwards. Actually, we didn't know that it was about health at all. We were just told to show up with the children" (pre-school teacher - study 1). As a result of this lack of health-focus only very few children touched upon any health issues in their initial description of the play and the ones who did were the ones who came from health-focused families and already observed 
themselves as healthy. In other words, the children were not prepared or motivated to reflect upon the health issues in the performance and as a result they acquired very little in terms of new health knowledge, new ways of connecting existing knowledge to their own health behaviour and, perhaps most importantly, ways of relating the health information to their health identities.

\section{Health identities are developed in social settings and social relations}

Across the studies, the children and adolescents are highly aware of the connections between health and their social spheres and group affiliations: "It's all about which school you attend. I remember at my old school there was this thing about if you were very focused on health you were seen as kind of boring and bookish. And all the cool kids would drink Coke and eat crisps and stuff like that... People get a lot of respect from me when they tell me they're vegan or something like that. That takes a lot of willpower. It's the same with living a healthy life; it's not something you just do." (Girl, ninth grade - Study 3) This girl (or rather her psychological system) actively observes how health and healthy behaviour is observed differently by people from different schools and she also observes how there are significantly different imaginaries and expectations associated with these different observations. In one school, health might be an area important enough to be different within, whereas it might be deemed unimportant in another school. In some school classes being healthy gives status, meaning that possessing health knowledge and behaving healthily gives you a prominent place in the hierarchy. In other school classes, however, what gives status is something completely unrelated to health, and accordingly health and healthy behaviour have low priority.

Regarding the very different levels of physical activity across classes, the children are also highly reflective concerning why and how these levels exist and why the level in their class might be where it is: 'I've thought a lot about what would have happened if I'd ended up in the other class. Then I'd probably have a different personality altogether. I mean you're with these people five days a week and it's been like that for six or seven years. I guess you just change along with the people you're together with." "And the classes are really very different. I mean none of the boys in our class plays football. They're all skaters and that's really unusual. So you really become the class you're in." (Girls, seventh grade - Study 3) Changing along with the rest of your class, or perhaps changing despite the behaviour of the rest of your class, is a result of the perpetual observation of meaning and of others' observations. These continually structure new ways of fitting in and, accordingly, new ways of defining and understanding identities.

The matter of changing according to group norms or group behaviour is not restricted to school. This girl is telling us about health behaviour in relation to the groups that the adolescents belong to in their leisure time: "It depends on what kind of people you hang out with. There are groups where it's really really cool if you smoke or drink a lot, and that's just really unhealthy. But there are also some groups where people think you're a loser if you smoke and drink, and then it's suddenly cool to be healthy. It really depends on who you hang out with." (Girl, eighth grade - Study 3). This is exactly what Taylor means when he is 
talking about horizons of significance. In some groups (or social systems) health issues are important enough to be different within and the health identities are therefore constructed and observed based on these health issues. In other groups the construction of communicative meaning is focused on other things than being healthy and this often leads to communicative meaning and social norms dominated by unhealthy behaviour. It is in these cases that the choice of being healthy is not always an active self-choice. If behaving thoroughly healthy means excluding yourself from the dominant group this will be a difficult choice to make and even more difficult to perform on a daily basis.

\section{The role of the family}

It is not only school classes and group affiliations that play a central role in the construction of health identities. The family also play a significant role in how children and adolescents understand and interpret themselves and each other as healthy and unhealthy: "I've tried it, where we made a bet at home. About that we weren't allowed to eat candy for a whole year. And if I could do that I got some presents. Among other things they gave me a mobile phone and an mp3-player. It was really hard, especially on the last day of school, where everyone just sits and eats sweets. But that's because my mother does not want us to get fat and be teased" (boy, second grade - Study 1). This boy communicates health as something negative and filled with restrictions. Throughout the interview, he continually refers to health as a "necessary evil" although he presented himself as completely healthy and as having substantial knowledge about all things related to health. He has clearly acquired his focus on health and attitudes towards anything health related from his home, and this has in many ways affected the structures with which he observes himself in contexts related to health. He insists on observing himself one-sidedly in contexts with a very clear health profile, but he does so because of the extremely negative imaginaries presented to him by his family. This boy is very young, and when he at a later stage is presented with different imaginaries and expectations from peers and society as a whole, he will no doubt experience complex problems concerning where and how to observe himself meaningfully - in other words: a potential health identity crisis.

The children and adolescents often talk about their families when discussing health issues. In some instances, health seems to be a joint project in which the whole family takes part. The health behaviour and health identities of the parents are, as indicated above, often directly adopted by the children: "I'm really healthy and it's because my mom is kind of fanatical about it at home and my dad makes buns with spelt flour and stuff like that. We just eat vegetables all the time and we never have any candy or sugar in the house at all. So I never have unhealthy food as an option and I really don't want to spend my own money on it either. I don't know what it'll be like when I move out on my own but I've been raised to live a healthy life and I think I'll just keep doing it this way." (Girl, seventh grade - Study 3) This statement exemplifies how health identities are relationally observed, understood and developed. Health has an identity-defining role in this girl's family, and "being healthy" is an important factor when the family members observe each other's identities. The ways in which this family observes other people will be based on expectational structures concerning how important it is to be healthy and what being healthy means. 


\section{Health identities are developed based on observations of the past, present and future}

Children and adolescents often explain that it is natural to be more or less healthy at various stages in life, and that they expect to be more or less healthy in the future: "I think that the older we get the healthier we're gonna get. I think we automatically want to focus more on our health." "Well, if I keep eating the stuff I eat now, then I really won't be healthy at all." "And we all know that. But I'm thinking that when you're young your body burns off the calories really fast and when you get older it just doesn 't and you end up getting fat." (Girls, ninth grade - Study 3) This tendency to ignore or justify the present state of unhealthiness by referring to how they will definitely be healthier when they grow up seems to be widespread. They do not seem to apply their current health behaviour to future health or future illnesses, and future unhealthiness does not seem to fit into their imaginaries. A group of boys discuss future physical exercise: "We'll have to be healthier in the future. Because the older we get, the less sports we'll do. When you're a kid you just run more because you play and things like that." "Maybe you just have more energy when you're younger." "Or maybe you have more energy when you're older, actually. Because you're stronger, but you just don't wanna use it. You'd much rather use it on the remote control." (Boys, seventh grade - Study 3)

The adolescents' observations and expectations regarding future health seem to depend on how they observe themselves meaningfully in the present. When it comes to health knowledge, the tendency is the same. The adolescents believe they will probably need more knowledge when they get older, but that they are fine for now. In other words, health knowledge is something you acquire when you are no longer healthy: "I know some things about health, but I don't know everything yet. The things I know are sufficient for now, but when I get older I'll probably need to know more. I mean when you leave home and you don't have your mom and dad to take care of you. My sister's always saying that she's learned this or that about health at her school and since I'm planning to attend the same school as her, because I'm interested in the same things as her, I'll probably learn the same things as well." (Boy, seventh grade - Study 3) Children and young people generally feel healthy - at least in the sense of not being ill. Knowledge is seen as something you acquire when it is needed rather than something you seek beforehand.

The apparent unimportance of present health returns us to the notion of only being able to develop and understand identities against a backdrop of things that matter. If health knowledge and health in general are viewed as things that do not matter when you are young, it will be challenging to present health knowledge in ways that appear relevant and observable. Children/adolescents with no interest in health find it hard to observe their identities in contexts focusing on health. This increases the risk of creating health identities with a widening difference between healthy and unhealthy children/adolescents - thereby creating further inequalities.

\section{Discussion}

The concept of health identity offers a new way of understanding children's and adolescents' acquisition of health knowledge and their subsequent health behaviour. It manages to look at how children and adolescents observe themselves and their own health, how they observe 
each other's health and how they are observed as healthy or unhealthy by teachers, parents and society as a whole. The concept enables us to get the full picture of how health is understood and acted upon on several levels. It is significant that even very young children observe each other as healthy and unhealthy, and there are ample examples of how teachers heavily influence these processes by observing children/adolescents as either healthy or unhealthy based on how they expect or imagine them to be more or less susceptible to health information and health education. Combining the data from the three studies, it is fair to conclude that health identities determine children's and adolescents' choices, values, expectations, imaginaries and sense of meaning with regard to health matters.

Knowledge of the existence of different health identities is pivotal when studying how healthy and unhealthy children and adolescents prioritize health campaigns and health information. Children and adolescents navigate in and acquire the presented knowledge and competences based on their health identity.

Studying health identities involves a perpetual focus on the contexts and settings within which children and adolescents observe their identities. Everything that is observed is observed within a particular setting and based on the predominant structures of observation in that setting. In the studies, it is clear that different settings provided the children and adolescents with varying opportunities to observe their health identity within the communicative meaning, showing us that health identity is observed when things matter.

Using a concept of health identity in health education also entails a focus on inequalities in health. The empirical data suggest that health education runs the risk of making healthy children and adolescents healthier and unhealthy children and adolescents unhealthier - by appealing primarily to those who are already interested in health and being healthy. Health identity theory focuses the health educational perspective on trying to make health matter to those who find health uninteresting - by focusing on making them want to observe their identities within health education settings they normally do not observe at all. The data show that this can be done by presenting health in alternative ways, thereby showing children and adolescents that health and being healthy do not always mean what they think they mean.

The much-debated missing link between health knowledge and health action also comes into play in relation to health identity. All of the interviewees, even the young children, know the basics of what constitutes healthy and what does not. The challenge is that some of them act upon this knowledge and some do not. The children/adolescents to whom health is important and who identify with being healthy act, for the most part, on their health knowledge. Other children/adolescents, to whom health is not important, do not. The data suggest that their health identity determines whether or not they act on the knowledge they have.

With regard to the theoretical construct of the concept of identity, it seems fair to conclude that an identity concept based on the ideas of Luhmann and Taylor manages to overcome the problem of having to distinguish between identity understood as a coherent core and identity understood as a multitude of patchwork identities. With identity being essentially constructed within the process of observation, the concept manages to merge these two approaches into one - by presenting identity as something recognizable, meaningful and observable yet still 
changeable, depending on the contextual and social differences that affect this process of observation. The concept also manages to present an approach to identity that does not suffer from being under-theorized and, therefore, difficult to theoretically apply. Luhmann's and Taylor's theories give the concept a solid complexity-oriented base, while still hanging on to the essential elements found in classic, traditional identity concepts.

\section{Implications for research and practice}

A central question that has not been explored here is how we should measure health identity. Thus far, the concept has been studied solely through interview studies. It would be more accessible for use in other studies and by other researchers if additional ways of exploring children's and adolescents' health identities could be developed. It would seem relevant to consider developing a questionnaire with relatively few items - based on which one would get an indication of the health identity of the individual child/adolescent and of the entire class/school. The questionnaire could use the five themes from the present paper as its main categories - thereby investigating expectations and imaginaries, the teacher's role, settings and relations, the family's role and observations of the past, present and future. By including all five themes we will get a complete picture of how health identity is developed on the basis of individual observations of communication in various contexts and is expressed through expectational structures and social imaginaries with an impact on health values, health beliefs and health choices. The questionnaire will show us how the individual child/adolescent and the class/school have a unique way of orientation and navigation in the complexities of health education, health information and possible health behaviours.

Introducing a new conceptual framework naturally entails a multitude of possible implications for health education practice and health education research. The concept - as a new way of understanding children's and adolescents' acquisition of health knowledge, their categorization of themselves as healthy or unhealthy and their subsequent health behaviour has profound implications for health education practice.

It is important to incorporate adolescents' social imaginaries and expectational structures into how health education is put into practice. If the school class is characterized by firmly established roles and hierarchies, health education needs to take this into consideration by presenting health in unexpected and alternative ways, thereby triggering new observations of health identity. When children/adolescents are presented with new contexts, they have to make sense of their own role within the context, and this entails new ways of imagining their present and future health and new expectations concerning it.

Basically, increased awareness of children's and adolescents' very different health identities and the structures that confirm them should be a central concern when working with health education. A child who can recognize him- or herself in a school's constructions of meaning, health and health education is more likely to perceive his or her own identity as meaningful and relevant in relation to health.

One of the strengths of the health identity concept is indeed this inherent focus on settings and on how settings are observed on the basis of complex structures of observation. The very 
fact that the concept describes something not strictly psychological and not strictly social enables the health education practitioner to focus on both aspects simultaneously. Maintaining a constant focus on how settings lead to different observations of health and different observations of themselves (children and adolescents) in relation to health will strengthen any health education initiative.

Given that it is a new way of theoretically grasping identity, the conceptual challenges and potentials are numerous and the concept will no doubt be challenged by identity scholars from both psychological and sociological traditions. These challenges will help shape and consolidate the concept, and it will also become apparent what other conceptual developments are compatible with the health identity concept. The present paper does not in any way constitute completion of the construction of the health identity concept, and the concept will certainly evolve over time through theoretical, methodological and empirical studies.

\section{References}

Bendle, M.F. (2002) The crisis of 'identity' in high modernity. British Journal of Sociology. Vol. 53, no. 1, 1-18. DOI: 10.1080/00071310120109302

Grabowski, D. (2013a) Identity, knowledge and participation: Health theatre for children. Health Education. Vol. 113, no. 1, 64-79. http://dx.doi.org/10.1108/09654281311293646

Grabowski, D. (2013b) Health-identity, participation and knowledge: A qualitative study of a computer game for health education among adolescents in Denmark. Health Education Journal. Vol. 72, no. 6, 761-768. doi: 10.1177/0017896912469559

Grabowski, D. \& Rasmussen, K.K. (2014a) Authenticity in health education for adolescents: A qualitative study of four health courses. Health Education. Vol. 114, no. 2, 86-100. http://dx.doi.org/10.1108/HE-06-2013-0020

Grabowski, D. \& Rasmussen, K.K. (2014b) Adolescents' health identities: A qualitative and theoretical study of health education courses. Social Science \& Medicine. Vol. 120, 67-75. doi:10.1016/j.socscimed.2014.09.011

Grace, M., Woods-Townsend, K., Griffiths, J., Godfrey, K., Hanson, M., Galloway, I., Azaola, M.C., Harman

K., Byrne, J. \& Inskip, H. (2012) Developing teenagers' views on their health and the health of their futurechildren. Health Education. Vol. 112, no. 6, 543-559. http://dx.doi.org/10.1108/09654281211275890

Hall, S. (2001) Who Needs Identity? In du Gay, P., Evans, J. \& Redman, P. (Eds) Identity: A Reader, Sage Publications Inc, London, 15-33.

Karnilowicz, W. (2011) Identity and psychological ownership in chronic illness and disease state. European Journal of Cancer Care. Vol. 20, 276-282. DOI: 10.1111/j.1365-2354.2010.01220.x 


\section{Macrothink}

Luhmann, N. (1990) Essays on self-Reference. Columbia University Press, New York.

Luhmann, N. (1995) Social Systems, Stanford University Press, Palo Alto, CA.

Luhmann, N. (2002) Theories of Distinction, Stanford University Press, Palo Alto, Ca.

Marcia, J.E. (2014) From Industry to Integrity. Identity, Vol. 14, no. 3. DOI:10.1080/15283488.2014.924413

Mohajer, N. \& Earnest, J. (2010) Widening the aim of health promotion to include the most disadvantaged: vulnerable adolescents and the social determinants of health. Health Education Research. Vol. 25, no. 3, 387-394. doi: 10.1093/her/cyq016

Peters, L.W.H., Wiefferink, C.H., Hoekstra, F., Buijs, G.J., ten Dam, G.T.M. \& Paulussen, T.G.W.M. (2009) A review of similarities between domain-specific determinants of four health behaviors among adolescents. Health Education Research. Vol. 24, no. 2, 198-232. http://dx.doi.org/10.1093/her/cyn013

Petraglia, J. (2009) The importance of being authentic: Persuasion, narration, and dialogue in healthcommunication and education: Health Communication. Vol. 24, no. 2, 176-185. DOI:10.1080/10410230802676771

Prelip, M., Kinsler, J., Thai, C.L., Erausquin, J.T. \& Slusser, W. (2012) Evaluation of a School-based Multicomponent Nutrition Education Program to Improve Young Children's Fruit and Vegetable Consumption. Journal of Nutrition Education and Behaviour. Vol. 44, no 4, 310-318. DOI: http://dx.doi.org/10.1016/j.jneb.2011.10.005

Taylor, C. (1991) The Ethics of Authenticity, Harvard University Press, Cambridge.

Taylor, C. (2004) Modern Social Imaginaries, Duke University Press, Durham, NC.

Vickers, N. (2012) Narrative identity and illness. Journal of Evaluation in Clinical Practice. Vol. 18, 1070-1071. DOI: 10.1111/j.1365-2753.2012.01919.x

Waterman, A.S. (1984) Identity Formation: Discovery or Creation? The Journal of Early Adolescence. Vol. 4, no. 4, 329-341. doi: 10.1177/0272431684044004

Wistoft, K. (2010) Health Strategies and reservoirs of knowledge among adolescents in Denmark. Global Health Promotion. Vol. 17, no. 2, 16-24. doi: 10.1177/1757975910365233

Yanos, P.T., Roe, D. \& Lysaker, P.H. (2010) The Impact of Illness Identity on Recovery from Severe Mental Illness. American Journal of Psychiatric Rehabilitation. Vol. 13, no. 2, 73-93. DOI:10.1080/15487761003756860 